\title{
Contribuição do Ecoturismo e Educação Ambiental em um balneário localizado no município de Nobres (MT)
}

\section{Contribution of Ecotourism and Environmental Education at a resort located in the city of Nobres (MT, Brazil)}

\author{
Maysa Teodoro Lemes, Josué Ribeiro Nunes, Paula Alexandra Nunes, \\ Simone Santos Oliveira
}

\section{RESUMO}

O ecoturismo surge como uma nova tendência de turismo alternativo que visa conciliar lazer com o mínimo de impactos na natureza. Neste contexto, o ecoturismo vem se mostrando um segmento que apresenta grande crescimento dentro da área de turismo, pois está relacionado com a renda que é gerada e pelo aumento de ecoturistas que buscam o equilíbrio do homem com a natureza. A educação ambiental entra como uma aliada nas práticas do ecoturismo, contribuindo para a formação de pessoas conscientes de seus atos com a natureza. O objetivo deste trabalho foi analisar como o Ecoturismo e a Educação Ambiental contribuem na prática do turismo, em áreas naturais, usando como objeto de estudo um balneário, localizado a $140 \mathrm{~km}$ da capital Cuiabá, situado a 14²'10.7'S e 05'21'54.2"O região centro-oeste. Para a obtenção de dados, foram aplicados questionários aos turistas, proprietários e funcionários, além de verificar quais atividades ecoturísticas estão sendo realizadas no balneário. Os resultados demonstraram que o balneário possui como atividades, filmagens da paisagem, caminhadas em trilha de chão batido e atividades de bóia cross, realizadas até 2011 . Em relação aos resultados obtidos com as entrevistas aos turistas, observou-se que os mesmos possuem informações a respeito do ecoturismo, meio ambiente e educação ambiental, porém é preciso que seja implementado no balneário, um planejamento ambiental que melhore o envolvimento dos turistas com o meio ambiente, fazendo com que as práticas ecoturísticas sejam respeitadas e contribuam para o desenvolvimento sustentável do local. Para os proprietários e funcionários, observou-se que há pouco conhecimento sobre as questões ambientais e o ecoturismo. Enfim, nesta pesquisa percebeu-se que ainda que a atividade desenvolvida seja chamada de ecoturismo, não guarda relação com a mesma, pois não é trabalhada a questão da conservação ambiental e do desenvolvimento econômico local.

PALAVRAS-CHAVE: Turismo; Ambiente; Áreas Naturais. 


\begin{abstract}
Ecotourism emerged as a new trend of alternative tourism that aims to combine leisure with minimal impacts on wildlife. In this context, ecotourism has proven to be a segment that has great growth within the area of tourism, because it is related to income that is generated and the increase of eco-tourists seeking a balance between man and nature. Environmental education enters as an ally in the practice of ecotourism, contributing to the formation of people aware of their actions with nature. The objective of this study was to analyze how ecotourism and environmental education contributes to the practice of tourism in natural areas as study object using a resort located $140 \mathrm{~km}$ from Cuiabá, located at $14^{\circ} 42^{\prime} 10.7^{\prime \prime S}$ and $05^{\circ} 21^{\prime} 54.2^{\prime \prime}$ OMidwest region. To obtain data, questionnaires were administered to tourists, owners and employees, and check which ecotourism activities are being held in the resort.The results showed that the resort has activities like, filming the landscape, walking on the dirt track and cross buoy activities carried out by 2011 . Regarding the questionnaires from tourists, it was observed that they have information about ecotourism, the environment and environmental education, but it needs to be worked in the resort, environmental policies that improve the involvement of tourists to the environment, causing that ecotourism practices are respected and contribute to the sustainable development of the site. For owners and employees, it was observed that there is little knowledge about environmental issues and ecotourism, as their attitudes reflect in the resort. Enfim, nesta pesquisa percebeu-se que ainda que a atividade desenvolvida seja chamada de ecoturismo, não guarda relação com a mesma, pois não é trabalhada a questão da conservação ambiental e do desenvolvimento econômico local.Finally, in this research it was perceped that, still the activity developed was called ecotourism, it is not related with, because it not works with environmental conservation and local econoic development.
\end{abstract}

KEYWORDS: Tourism; Environmental; Protects Areas.

\title{
Introdução
}

Nos últimos anos com o aumento da globalização, observou-se um crescimento na preocupação com questões socioambientais relacionadas com os danos que o processo de desenvolvimento vem causando ao meio ambiente (FARIA, 2002). Essas questões contribuem para a sensibilização das pessoas em torno dos problemas ambientais e consequentemente fazem com que as mesmas busquem alternativas que visem 0 desenvolvimento sustentável.

Neste contexto em particular, o ecoturismo vem se mostrando o segmento que apresenta maior crescimento dentro da área de turismo (NEIMAN \& RABINOVICI, 2002), pois busca o equilíbrio do homem com a natureza de uma forma sustentável, sem prejudicar o meio ambiente, gerando renda através do aumento no número de ecoturistas (PEDRINI, 2007).

Fennell (2002), Pires (2002) e outros autores com base em conhecimentos culturais de várias regiões do Brasil e do mundo, vêm criando conceitos para explicar essa nova tendência do mercado de turismo. Costa (2002, p.9) enumera algumas características gerais sobre 0 ecoturismo: 
1.Toda forma de turismo em que a motivação principal dos turistas é a observação e a apreciação da natureza, bem como as culturas tradicionais que prevalecem nas áreas naturais; 2. Contém elementos educacionais e tradicionais; 3. Procura reduzir ao mínimo os impactos negativos sobre o entorno natural e sociocultural, além de contribuir para a proteção de áreas naturais incrementando a conscientização para a conservação de recursos naturais entre habitantes e turistas.

Essas características contribuem para a grande importância do ecoturismo no mundo atual, pois as populações humanas buscam na natureza obter lazer com o compromisso de respeitar a diversidade local. Mas, apesar de sua importância ainda faltam muitos estudos sobre essa área que cresce gradativamente no Brasil e no mundo (PEDRINI, 2005).

Tendo como base o respeito à natureza, a educação ambiental entra como uma aliada na prática do ecoturismo e tem como um dos principais objetivos, formar cidadãos conscientes de sua relação com a natureza e seu habitat, para que através do uso racional de recursos naturais, as futuras gerações possam também usufruir destes benefícios (NEIMAN; RABINOVICI, 2002).

Contudo a educação ambiental abrange inúmeras áreas, podendo ser trabalhada nos mais variados contextos. Dentre eles, destacam-se as atividades que permitem um contato direto com a natureza, como o estudo do meio, trilhas interpretativas, e o ecoturismo. Para instrumento de desenvolvimento da educação ambiental essas atividades devem ocorrer não de forma pontual, mas enfatizando aspectos econômicos, sociais, políticos, culturais e éticos, deixando espaço para a construção de valores respeitando os seres humanos e a vida (TOLEDO, 2006).

Uma das linhas de ação e estratégias do governo no Programa Nacional de Educação Ambiental (PRONEA, 2005, p.44) visa:

\begin{abstract}
Estímulo e apoio à inserção da educação ambiental nas práticas de ecoturismo, visando garantir a sustentabilidade social, ecológica e econômica das comunidades receptoras e proporcionando uma interação adequada dos visitantes com os ecossistemas locais.
\end{abstract}

Sendo assim, a inserção da educação ambiental nas atividades ecoturísticas, contribui para ações transformadoras no desenvolvimento sustentável, porém as mudanças de comportamento só ocorrerão quando a sociedade, em geral, tiver consciência de suas atitudes perante a natureza (COSTA; COSTA, 2005). Diante do exposto, este trabalho tem por objetivo analisar como o ecoturismo e a educação ambiental, contribuem na prática do turismo em áreas naturais, usando como objeto de estudo um balneário no município de Nobres, MT. 


\section{Material e método}

\section{Área de estudo}

O município de Nobres está localizado a $140 \mathrm{~km}$ da capital Cuiabá, região Centro Oeste do Estado de Mato Grosso, possuindo uma grande diversidade de pontos turísticos que são privilegiados pela localização que é rica em recursos naturais e artificiais (GUIMARES, ZAVALA, 2008).

O balneário ${ }^{1}$ pesquisado encontra-se no município de Nobres MT,situado nas coordenadas 14 $42^{\prime} 10.7^{\prime \prime S}$ e $05^{\circ} 21^{\prime} 54.2^{\prime \prime O}$ (Figura 1). A extensão total da área é de 273 hectares, tendo três cachoeiras e área de lazer que contém campo de voleibol e uma piscina. O estabelecimento recebe turistas desde 2009, antes era frequentado apenas por familiares dos proprietários.

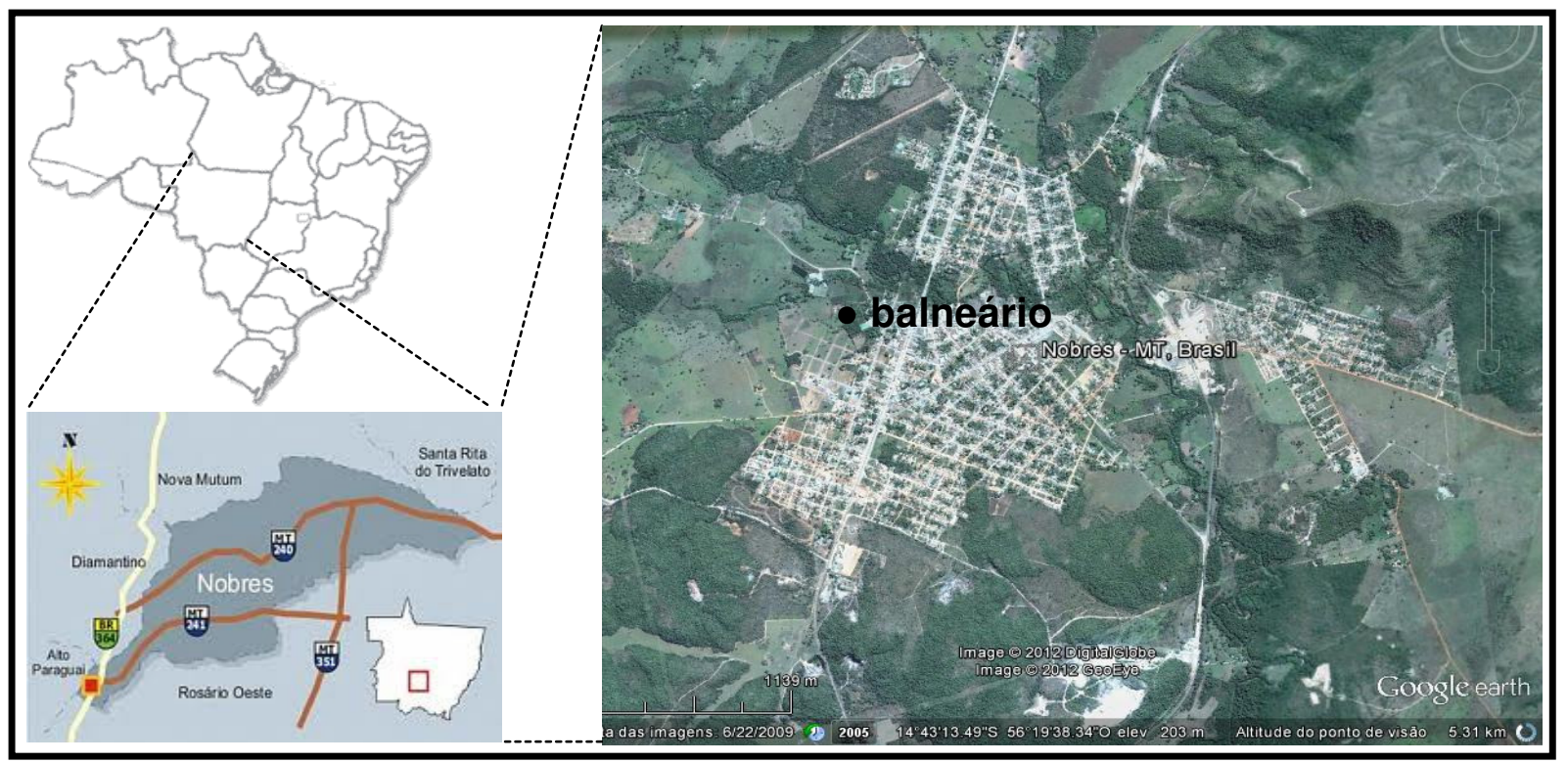

Figura 1: Localização da área de estudo do balneário no município de Nobres (MT). Adaptado de Google Earth 2012.

Figure 1: Study area localization at the balneário in the Nobres municipality (MT), made from Google Earth 2012.

\section{Metodologia}

Para a obtenção de dados, foram aplicados questionários (Figura 2) semi estruturados de forma aleatória, combinando perguntas fechadas e abertas em que o entrevistado descreveu livre e espontaneamente as suas respostas, sem condições prefixadas pelo autor da pesquisa (MINAYO, 1994).

O trabalho de campo foi realizado no mês setembro de 2011,para verificações in loco, a fim de estabelecer um contato com os proprietários e turistas. Para os proprietários e funcionários foram aplicados dois questionários, contento 14 perguntas, com a finalidade de saber o que a atual gestão entende por ecoturismo e educação ambiental, além de verificar de quais maneiras estas atividades estão sendo desenvolvidas. 
Para os turistas foi aplicado um questionário contendo 12 perguntas que abordavam assuntos semelhantes aos dos proprietários, sobre a concepção dos mesmos a respeito do local visitado. Os questionários foram baseados no trabalho de Almeida e Nunes (2010). Os dados obtidos foram tabulados e colocados nos gráficos, através de representações em números relativos (\%) (Figura 02$)$.

ROTEIRO DE ENTREVISTA PARA OS CLIENTES
1) Nome:
2) Sexo
3) Idade

ROTEIRO DE ENTREVISTA PARA PROPRIETÁRIOS E FUNCIONÁRIOS

1) Nome:

2) Sexo () F ( ) M

3) Idade ( ) 10 a 15 ( ) 16 a $20 \quad$ ( ) 21 a $26 \quad$ ( ) 27 a 30

( ) igual ou acima de 31

4) Profissão:

5) Escolaridade:

( ) analfabeto

( ) alfabetizado

( ) ensino fundamental completo

( ) ensino fundamental incompleto

( ) ensino médio completo

( ) ensino médio incompleto

( ) ensino superior completo

( ) ensino superior incompleto

6) Cidade/ Estado/ Pais de origem.

7) Qual a destinação final do lixo gerado na instalação?

8) Qual a destinação final dos efluentes (esgotos) dos

banheiros da instalação?

9) Qual o tratamento de água para o consumo humano?

10) O que o tema meio ambiente significa para você?

11) O que significa ecoturismo para você?

12) Para você o que significa Educação Ambiental?

13) Acredita que o ecoturismo contribui para Educação Ambiental

14) Você conhece a Proposta de Diretrizes para uma politica

Brasileira para o ecoturismo?

Fonte: adaptado por Almeida e Nunes, 2011.

Figura 2: Questionário utilizado para entrevista com proprietários, funcionários e turistas em um balneário no município de Nobres (MT).

Figure: Questionnaire used for the interview with the owner, employer and tourists at the

Balneário in the Nobres municipality (MT).

\section{Resultados e discussão}

\section{Identificação das atividades ecoturisticas oferecidas no balneário}

Pode-se observar no local o que Costa (2002) chama de ecoturismo "Light" e turismo de aventura. Para o ecoturismo 'Light', observaram-se atividades como fotografias, filmagens da paisagem e caminhadas contemplativas em trilhas de chão batido, já para o turismo de aventura são realizadas atividades como bóiacross.

Segundo os proprietários o bóiacross (Figura 3) foi praticado até 2011 no balneário, porém por falta de pessoas qualificadas para a prática deste e de empresas de turismo autorizadas, a atividade foi suspensa no local. Contudo, os proprietários pretendem qualificar-se a fim de retomar o bóiacross e implementar atividades de lazer no balneário. 


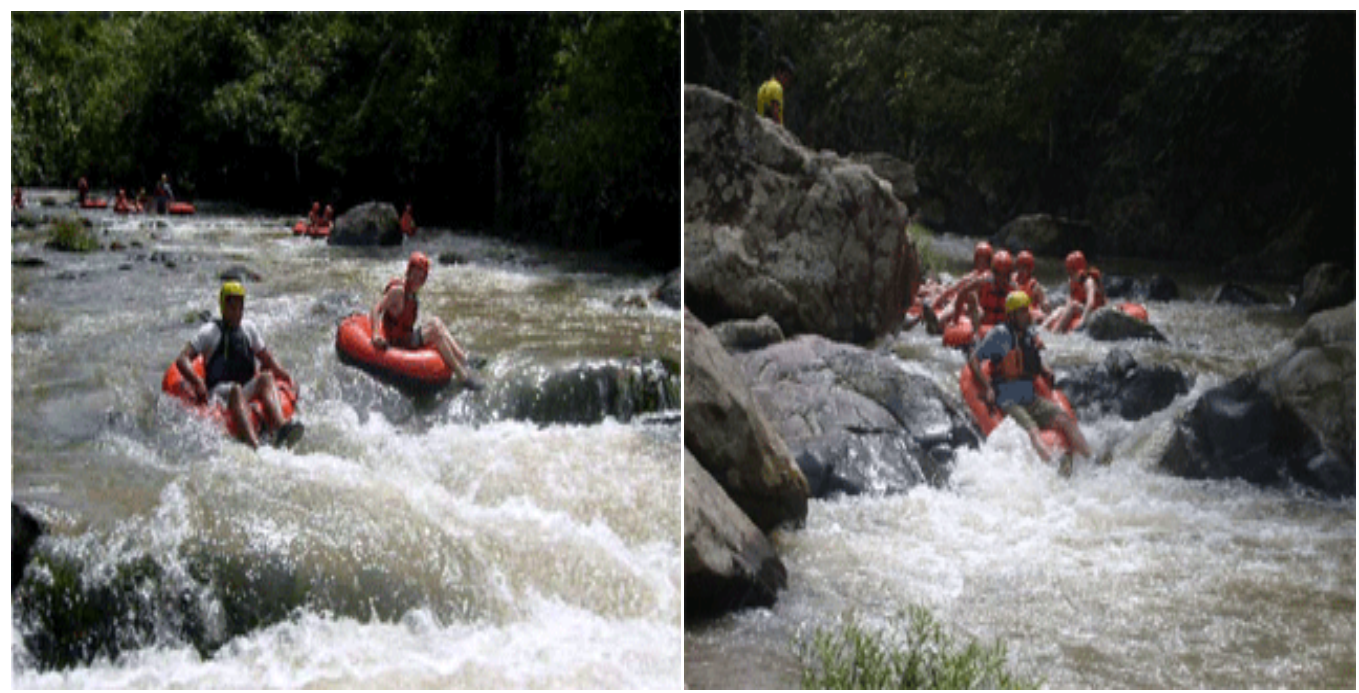

Figura 3:Turistas praticando bóiacross em um balneário no município de Nobres (MT). Fonte: http://www.mtcidades.com.br/cidades/cidadesn-o/nobres/pontosturisticosnobres.htm.

Figure 3: Tourists practicing boia cross into the balneário in the Nobres municipality (MT).

Em entrevista realizada com o secretário de turismo do município, a respeito dos pontos turísticos, o mesmo relatou que todos os locais turísticos de Nobres estão passando por vistorias através de uma empresa de consultoria da área. O secretário assegurou que situações legais e fundiárias, estrutura do local e outros assuntos estão sendo discutidos com os proprietários para a regularização dos problemas detectados. Isso demonstra o interesse do poder público para a conscientização dos proprietários a respeito de questões como segurança e impactos ambientais potenciais que cada local ou atividade apresenta.

\section{Caracterização dos questionários dos turistas}

Foram aplicados um total de 41 questionários para os turistas. Destes, $56,1 \%$ (23) eram do sexo masculino e $43,9 \%$ (18), do sexo feminino, dentre os grupos entrevistados alguns eram formados exclusivamente por rapazes, que visitavam o local em busca de aventura. Resultados similares foram obtidos no trabalho de Pedriniet al. (2010), em Ubatuba SP, em que se observou que a maioria $54,35 \%$ dos entrevistados eram do sexo masculino. Nesta pesquisa, a faixa etária dos participantes foi distribuída da seguinte forma, houve predominância das idades de 21 a 26 anos para os homens (48\%) e mulheres (39\%) e uma baixa predominância entre 10 a 15 anos, representando para o sexo masculino0\% e $6 \%$ para o feminino (Figura 4 a e b), a maioria dos entrevistados nesta pesquisa são jovens trabalhadores interessados em atividades que possam ser realizadas em ambientes naturais. Para Almeida e Nunes (2010), a grande predominância de visitantes jovens em locais turísticos, representa a afinidade que os mesmos têm com o meio ambiente. Dessa forma, os jovens contribuem para a manutenção de ambientes naturais no país, pois formam um grupo com grande poder de decisão. 

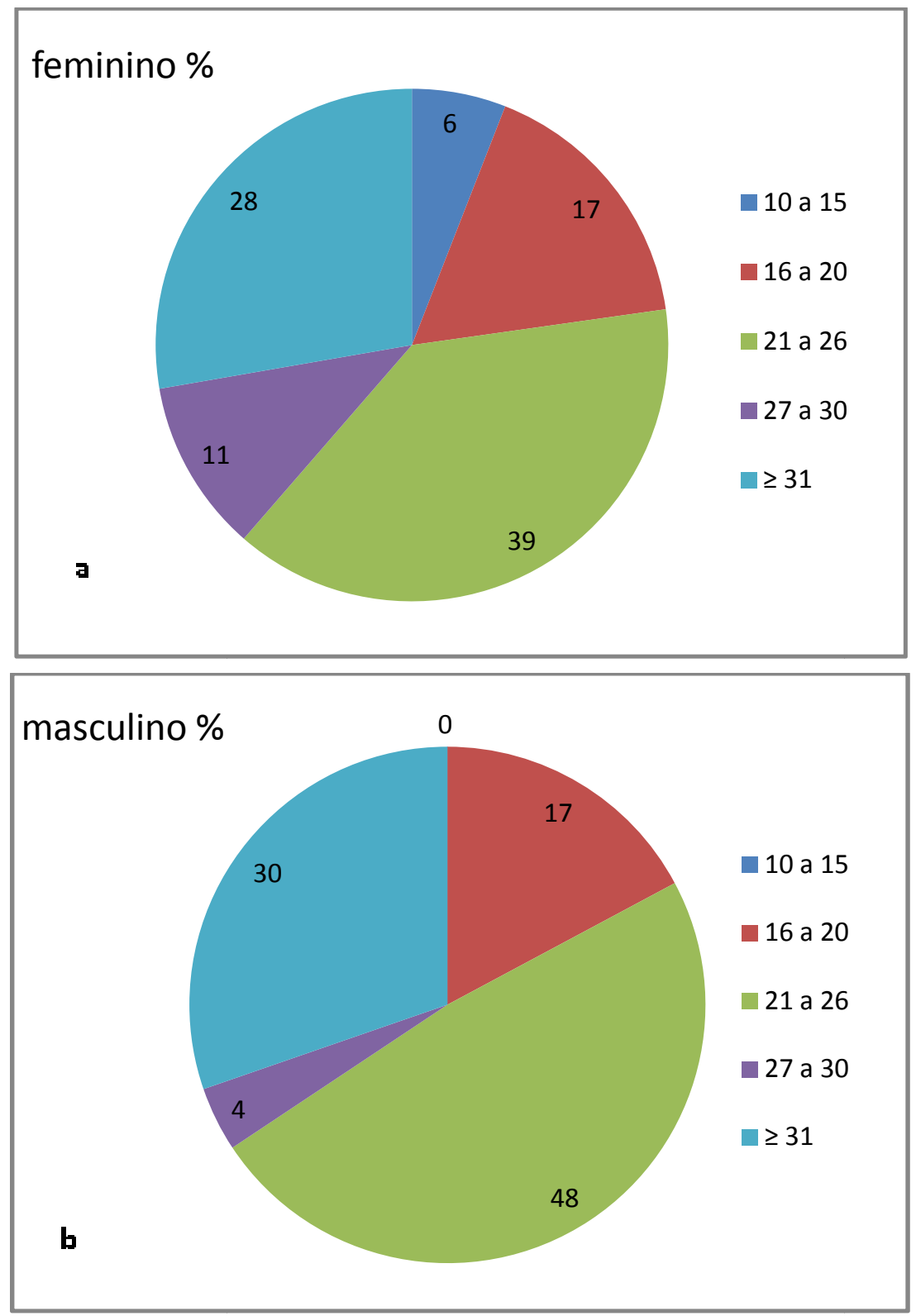

Figura 4: Faixa etária dos turistas, a- sexo feminino e b-sexo masculino que visitaram o balneário no período de setembro de 2011.

Figure 4: Age of tourists, a- female and b- male, which visited the bathhouse during September of 2011.

No que diz respeito ao nível de escolaridade dos entrevistados (Figura 5), é interessante notar que $45 \%$ das mulheres e $65 \%$ dos homens concluíram ou estavam cursando o ensino superior.

Os resultados corroboram com os de Ladeira et al. (2007), que observaram um alto nível de escolaridade entre os visitantes do Parque Estadual do Ibitipoca (MG), com isso espera-se uma maior sensibilização com relação a questões voltadas a educação ambiental, já que estes tiveram acesso ao ensino superior e consequentemente deveriam ser mais conscientes o que poderia favorecer a preservação dos atrativos e a infra estrutura do local. Por isso, é importante a sensibilização desse tipo de 
turista, no intuito de contribuírem para a conservação do ambiente (ALMEIDA; NUNES, 2010).

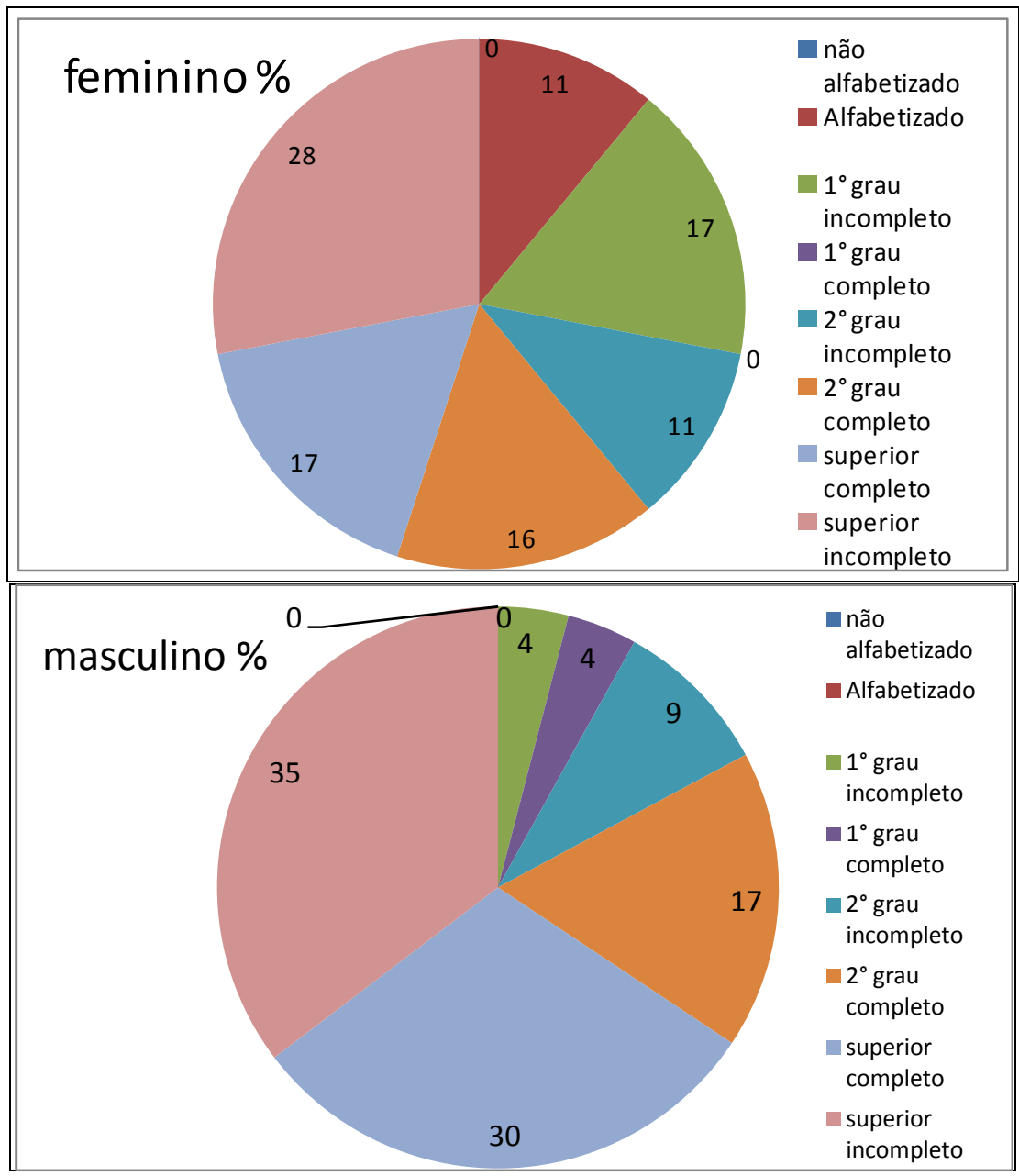

Figura 5: Nível de escolaridade dos turistas entrevistados em um balneário no município de Nobres (MT).

Figure 5: Scholar level of the tourists interviewed at the bathhouse in the Nobres municipality (MT).

Em relação às próximas questões, todas foram analisadas num contexto geral, sem distinção de gênero. Quanto à origem (Figura 6) podese observar que mais da metade dos turistas, ou seja, $53,65 \%$ são do município de Nobres - MT, onde está localizado o balneário, facilitando assim, o deslocamento dos próprios moradores para frequentar 0 estabelecimento, este fato leva a reflexão do sentido de pertencimento que cada turista pode ter do local, já que são do município, o que poderia facilitar a sensibilização quanto a educação ambiental. Do total de entrevistados $75,56 \%$ são do estado de Mato Grosso, ou seja o turismo é realizado predominantemente por pessoas do local, a maioria dos entrevistados que não são do estado de Mato Grosso estavam visitando parentes na região e foram levados ao local por eles. Também é importante observar que $82,82 \%$ dos entrevistados já haviam visitado o local, o que corrobora o observado na Figura 6. 


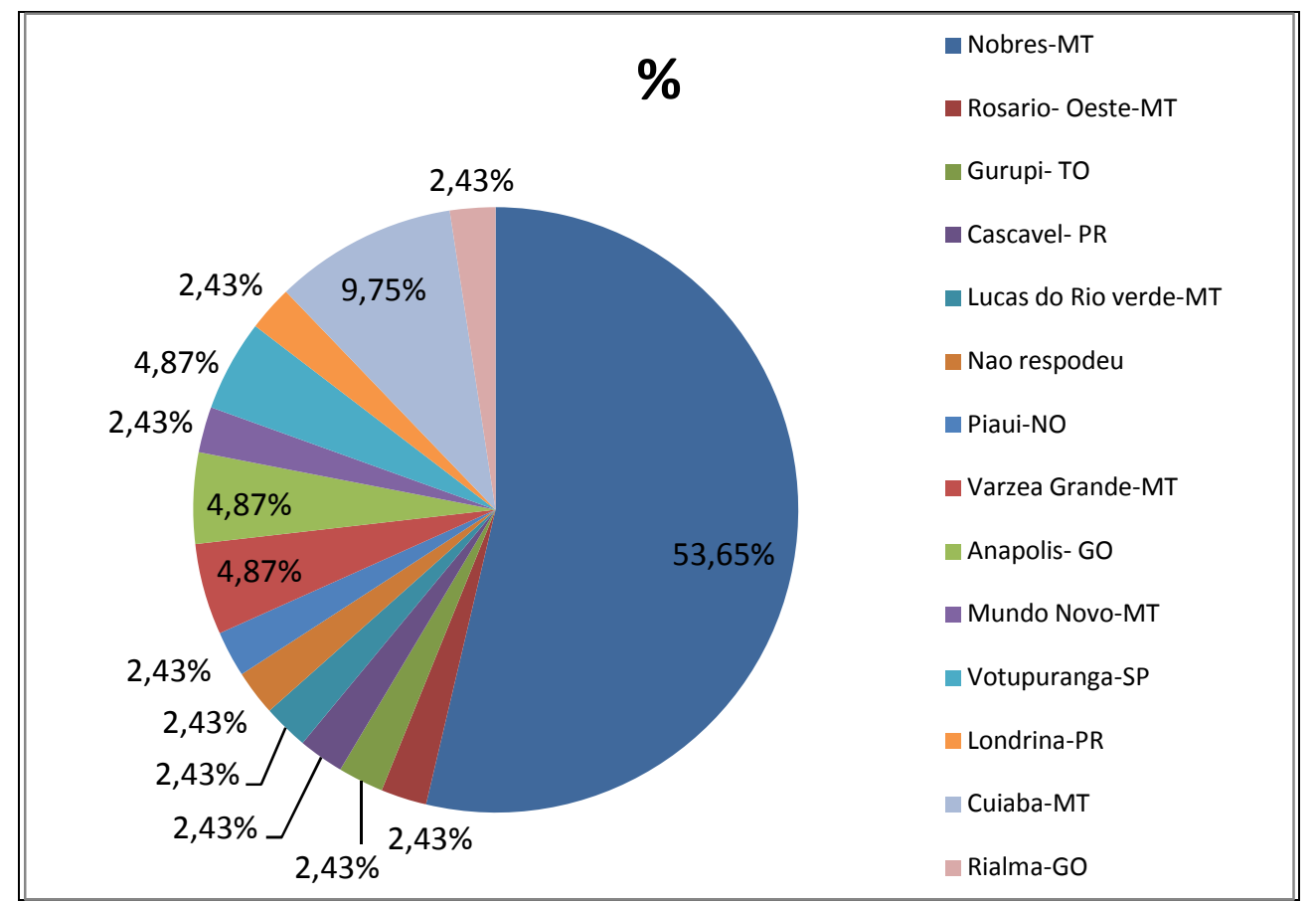

Figura 6: Origem dos turistas entrevistados em um balneário localizado no município de Nobres (MT).

Figure 6: Origin of the tourists interviewed at the bathhouse located in the Nobres municipality (MT).

Dentre os entrevistados, observa-se que $78,04 \%$ possuem atividades ocupacionais remuneradas, o que é relevante, pois o balneário cobra um preço significante para que os turistas usufruam dos serviços prestados, podendo selecionar o turista que tem acesso ao local, refletindo na questão do elevado nível de escolaridade encontrado.

Quando questionados sobre o que os motiva a visitar o balneário, $26,82 \%$ responderam que o lazer é um dos principais motivos e $19,51 \%$ consideram o local agradável. Já no trabalho de Vaz (2010), apreciar a natureza e relaxar foi um dos principais motivos para a visitação dos turistas no Parque Estadual do Açude da Concórdia (RJ). Para Martins Júnior (2005, p.64), "A fadiga, o excesso de trabalho, o crescimento desordenado das cidades e outros fatores, faz com que o homem necessite de atividades que livrem do estresse diário".

Outra questão abordada no questionário foi o significado do meio ambiente para cada um, nota-se que 59\% (Figura 7 ) responderam a natureza como sendo o significado do mesmo. É preocupante quando as pessoas colocam apenas a natureza como representativo do meio ambiente, pois o turista se exclui do sistema biológico. Para Sauvé (2005, p.317) "Na origem dos atuais problemas socioambientais existe essa lacuna entre o ser humano e a natureza que é importante eliminar. É preciso reconstruir nosso sentimento de pertencer à natureza, a esse fluxo de vida de que participamos". 


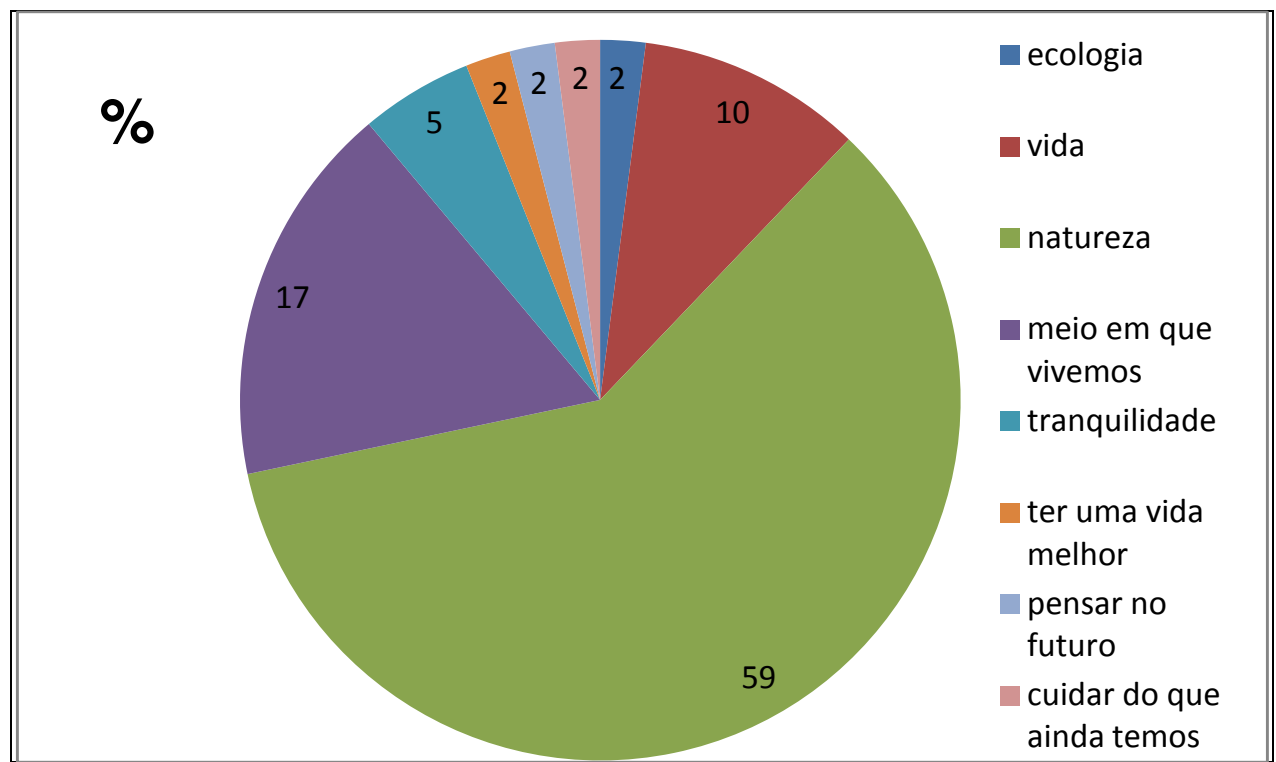

Figura 7: Significado do meio ambiente para os turistas entrevistados em um balneário localizado no município de Nobres (MT).

Figure 7: Environment meaning for tourists interviewed at the bathhouse in Nobres municipality (MT).

Neste contexto, uma das aliadas para a formação da construção de um novo pensamento, é a educação ambiental que deve ser trabalhada junto com o ecoturismo, levando em consideração os aspectos econômicos, sociais, políticos, éticos, culturais, deixando um espaço para a construção de novos valores, respeitando sempre homem e a natureza (TOLEDO, 2006).

Além disso, observou-se que $17 \%$ responderam que o meio ambiente significa o meio em que vivemos, ou seja, estas pessoas tiveram em sua formação a consciência de que o meio ambiente envolve tudo em nossa volta. Sato (1997, p.10) entende que:

Nessa concepção, esse é o nosso ambiente do cotidiano, na escola, nas casas, na vizinhança, no trabalho e no lazer. Esse ambiente é caracterizado pelos seres humanos, nos aspecto sócio- culturais tecnológicos e componentes históricos. Esse é o nosso ambiente, esse que nós devemos aprender a apreciar e desenvolver o senso de pertencer. Nós devemos cuidar do "nosso espaço de vivência".

Entende-se que os turistas possuem informações sobre o meio ambiente, porém é preciso que seja trabalhado no balneário, políticas ambientais que melhorem o envolvimento dos turistas, fazendo com que as práticas ecoturísticas sejam respeitadas e contribuam para 0 desenvolvimento sustentável do local.

Com relação aosignificado do ecoturismo, observou-se que $22 \%$, (Figura 8) relacionaram o ecoturismo com turismo ecológico, 15\% com 
sustentabilidade, $10 \%$ desfrutar da natureza sem prejudicar, $5 \%$ geração de renda e $2 \%$ relacionaram com turismo em áreas de fazenda e propriedades, os que não responderam ou deram respostas ilegíveis, totalizaram $15 \%$. As respostas dos turistas estão de acordo com Mendonça e Neiman (2002), que descreveram o setor de ecoturismo como uma área que possibilita o contato dos indivíduos com os espaços naturais garantindo a sustentabilidade e a geração de renda para o local.

Contudo, no trabalho de Almeida e Nunes (2010) 33\% dos entrevistados, relacionaram o ecoturismo coma conscientização ambiental. Os turistas apontam de forma geral o que é o ecoturismo, por isso, acreditase que tenha uma compreensão do que vem a ser essa nova forma de turismo.

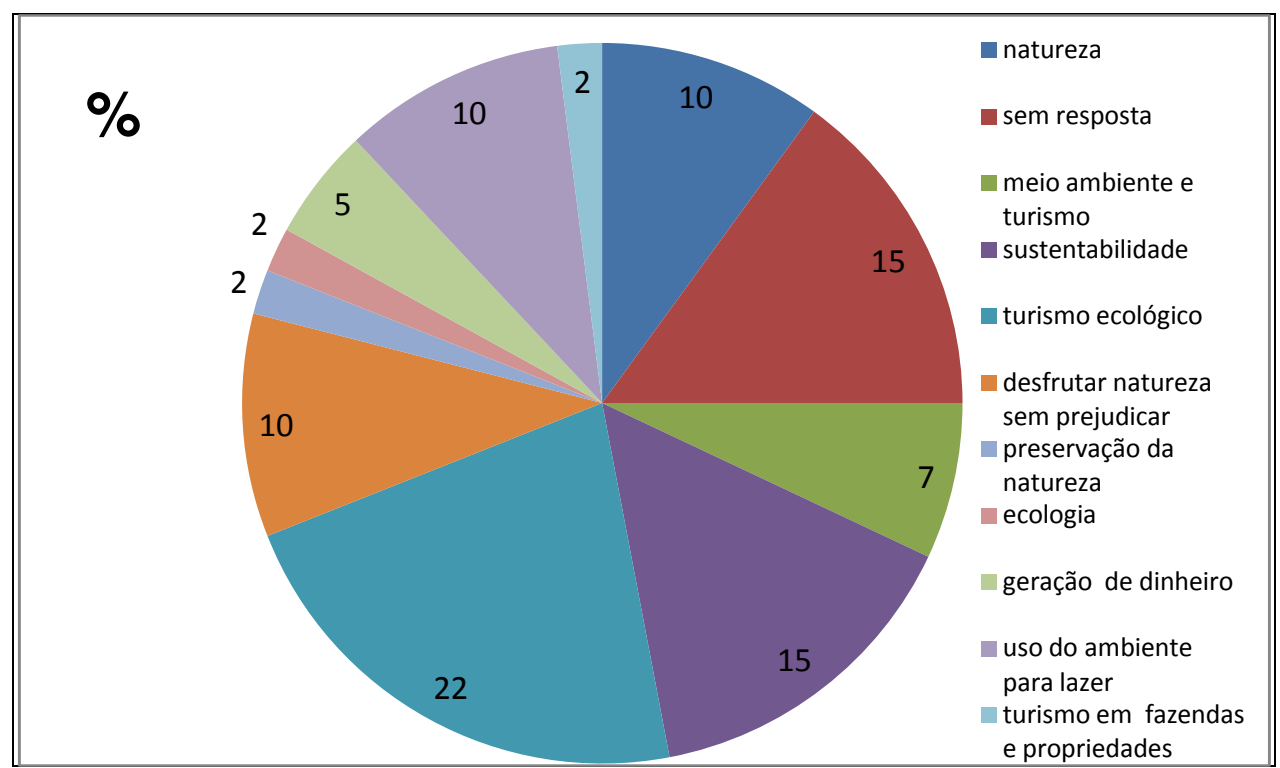

Figura 8: Concepção do ecoturismo para os entrevistados em um balneário no município de Nobres (MT).

Figure 9: Ecotourism conceptions for the interviewed at the in the bathhouse Nobres municipality (MT).

O município de Nobres- MT vem destacando a questão do ecoturismo, em vários eventos realizados na cidade, pois a mesma será um dos principais pontos turísticos para a Copa do Mundo de 2014, já que Cuiabá, a capital do estado será uma das sedes dos jogos. Todavia, ainda falta muito a ser feito para melhorar não só a infraestrutura dos locais, mas também a conscientização da população com relação às questões ambientais e trabalhar em conjunto o ecoturismo com educação ambiental.

Em relação ao significado da educação ambiental, 37\% (Figura 9) responderam que a educação ambiental é o meio ambiente preservado, $17 \%$ que é a conscientização ambiental, $24 \%$ respeitar a natureza, e $5 \%$ cuidar da natureza. Quando se fala em educação ambiental é importante lembrar que ela é um dos veículos transformadores de atitudes humanas perante a natureza, tendo como missão não só contribuir para a construção de uma sociedade sustentável, mas também promover o processo de 
educação ambiental, voltado para valores humanistas, conhecimentos, atitudes e competências que contribuam para a participação da população na construção de uma nova sociedade (PRONEA, 2005).

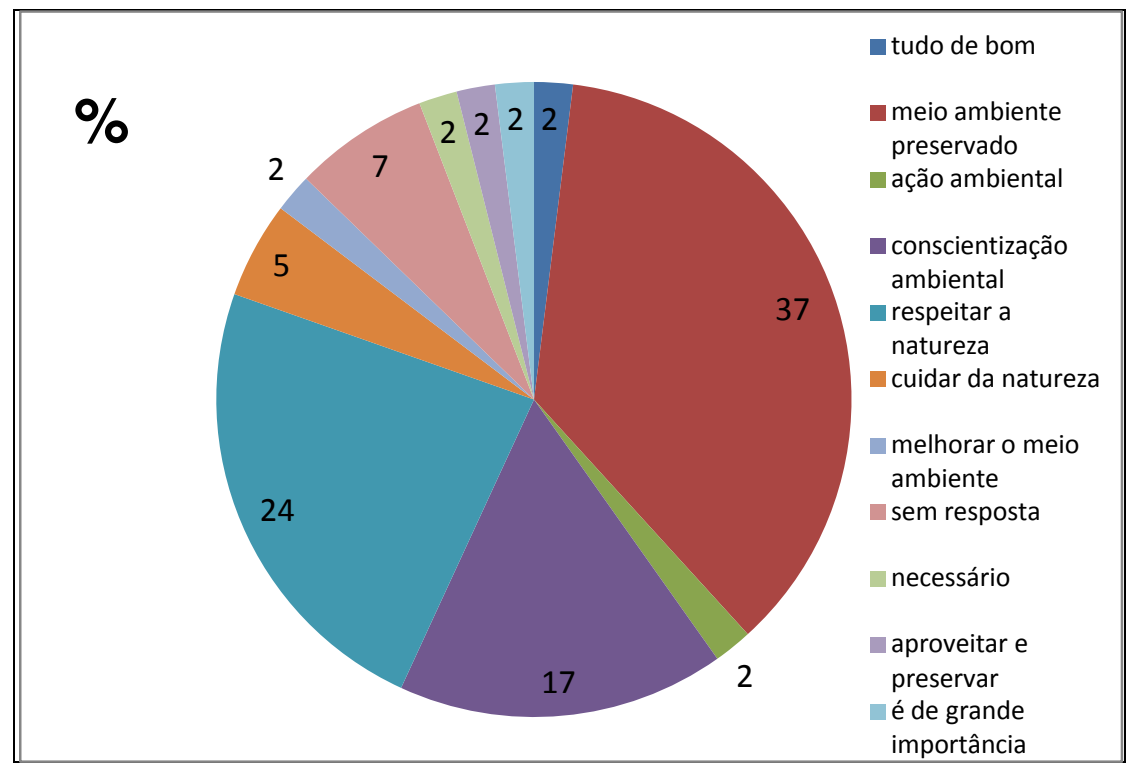

Figura 9: Significado da educação ambiental segundo os turistas em um balneário no município de Nobres (MT).

Figure 9: Meaning of Environmental education for the tourists in the bathhouse in the Nobres municipality (MT).

As respostas apontadas pelos turistas exprimem seu conhecimento empírico sobre o assunto e este fator é importante para a construção da educação ambiental já que, a mesma depende da consciência, conhecimento, comportamento, habilidades e participação da população para que a construção da educação ambiental seja realizada de forma satisfatória (DIAS, 2000).

Os turistas também foram questionados quanto à contribuição do ecoturismo para a educação ambiental, $87,87 \%$ responderam que 0 ecoturismo facilita a educação ambiental o restante não soube responder. Em uma das linhas de ação e estratégia da ProNEA, a educação ambiental entra como uma aliada na prática do ecoturismo, contribuindo para a interação do turista com o ambiente em sua volta.

É importante destacar que não existe, trabalhar ecoturismo sem a educação ambiental, é preciso conciliar as práticas ecoturísticas com a sensibilização das pessoas acerca do meio ambiente. Para isso,a educação ambiental deve ser trabalhada, levando em consideração a construção de conhecimentos, capacitação de pessoas e a realização de trabalhos voltados para o presente e futuro (COSTA; COSTA, 2005).

Sendo assim, no âmbito do ecoturismo a educação ambiental ultrapassa as barreiras da comunicação e passa a ser continuamente uma construção de conscientização tanto dos visitantes quanto dos proprietários, como sendo a preservação um dos principais objetivos a serem atingidos. Neste sentindo, para completar a contribuição do ecoturismo na educação ambiental é preciso a prática correta do ecoturismo, aquela em que o turista 
sabe das suas responsabilidades, contribuindo para sustentabilidade do local com menos impacto possível (XAVIER, 2005). Apesar de o turismo no local ser oferecido como ecosturismo, concluímos que o mesmo não é realizado na área e que faz-se necessário maio conscientização e mesmo capacitação para que tal atividade possa de fato ser implementada.

\section{Caracterização dos questionários dos proprietários}

O questionário foi aplicado aos proprietários e a um funcionário ${ }^{2}$ do balneário e todos os entrevistados são naturais de Mato Grosso. Quanto à parte socioeconômica do questionário, ambos possuem mais de 31 anos de idade. Por parte dos proprietários, o balneário não é a única e nem a principal fonte de renda, pois possuem um hotel na cidade de Nobres (MT) e a esposa de um deles é professora. Quanto à formação, o funcionário possui o ensino fundamental incompleto e os proprietários o ensino médio.

Quando questionados sobre o destino dos resíduos sólidos gerados no local, os proprietários responderam que todos são armazenados em sacos plásticos e levados para a cidade. Uma alternativa que poderia ser adotada neste balneário é o que está demonstrado no trabalho de Almeida e Nunes (2010), que constataram que os proprietários da reserva particular realizam a coleta seletiva de plástico, metal e papel utilizados, contudo a cidade de Nobres não tem centro de coleta seletiva de lixo, sendo um dos problemas para o município.

Em relação à destinação final dos efluentes gerados no estabelecimento, os proprietários e o funcionário responderam que são canalizados para fossas sépticas. A respeito do tratamento de água, nas respostas obteve-se apenas "natural", pois toda a água utilizada no balneário é proveniente do rio.

O meio ambiente para os proprietários e o funcionário significa cuidado e preservação da natureza. Mais uma vez, nota-se que o homem exclui-sedo meio ambiente, além disso, diante das respostas compreendese que os responsáveis pelo balneário têm pouco conhecimento a respeito do significado do meio ambiente e do ecoturismo, já que suas atitudes refletem no desenvolvimento do local.

Da mesma forma, o ecoturismo é entendido por eles apenas como turismo natural, que é uma visão muito restrita diante da complexidade apresentada por Costa (2002). De acordo com o autor, quando se fala em ecoturismo deve se levar em consideração, a conscientização dos visitantes para conservação dos recursos naturais do local, redução de impactos sobre o meio ambiente e contém elementos educacionais e de interpretação.

É preocupante quando os próprios proprietários têm uma visão limitada sobre o ecoturismo, já que o balneário se propõe a desenvolve atividades ecoturísticas, isso demonstrando que os proprietários devem aprimorar seus conhecimentos em relação a essa prática de turismo que é aplicada no balneário. 
Neste contexto, é observado que os responsáveis pelo balneário pouco conhecem as Diretrizes para uma Política Nacional de Ecoturismo, que está presente em um livro de fácil acesso disponibilizado pelo Ministério de Turismo na internet. Tendo em vista que essas diretrizes podem trazer aos proprietários, informações necessárias para a administração do local e para as práticas corretas de ecoturismo, é de extrema importância que tomem conhecimento das mesmas. Todavia os órgãos responsáveis pelo turismo na cidade de Nobres- MT deveriam trabalhar mais na divulgação desse tipo de informação, que visa orientar os donos de empreendimentos para essa prática, que tem como finalidade utilizar de forma sustentável o patrimônio cultural e natural além de incentivar a sua preservação e a consciência ambientalista, promovendo o bem estar das populações (BRASIL, 2008).

A educação ambiental foi definida por eles como a conscientização para preservação do meio ambiente. Sendo assim, a educação ambiental tem como um dos seus princípios, formar cidadãos conscientes de sua relação da natureza com o meio ambiente (NEIMAN; RABINOVICI, 2002), facilitando $o$ indivíduo a adquirir conhecimento e levar o mesmo a desenvolver habilidades que possa sensibilizá-lo para a construção de uma sociedade preocupada com questões ambientais (DIAS, 2000). Apesar de demonstrarem conhecimento sobre educação ambiental, estes parecem não coloca-las em prática, embora o turismo no local seja vendido como ecoturismo.

De acordo com os administradores e o funcionário, o ecoturismo contribui para a educação ambiental. É importante que os proprietários tenham a consciência que o ecoturismo e a educação ambiental, são ferramentas que devem caminhar juntas, para que haja o equilíbrio sustentável do local, porém é preciso que a educação ambiental não esteja atrelada somente no conceito de ecoturismo, mas como característica básica no perfil dos ecoturistas e também daqueles que estejam envolvidos com a atividade (XAVIER, 2005). Infelizmente foi constatado através das observações no local que estas atividades não são aplicadas.

\section{Conclusão}

Este estudo possibilitou demonstrar que falta muito trabalho a ser realizado para a melhoria do ecoturismo e da educação ambiental no balneário, que apesar de ser uma propriedade privada, que anteriormente recebia somente familiares, a partir de 2009vem recebendo turistas e oferta o local como com atividade ecoturística, embora na prática isso não seja realizado.

Não foram visualizadas no estabelecimento algumas estruturas básicas, como placas informativas direcionando os turistas aos locais em que estão as cachoeiras, placas informando a direção da trilha e a questão de acessibilidade para os deficientes físicos, não se observou nenhuma estrutura que possa auxiliar o contato dos mesmos com a natureza.

A educação ambiental e o ecoturismo, não são trabalhados de acordo com a ProNEA e as Diretrizes para uma Política Nacional de Ecoturismo 
que se encontra no livro Ecoturismo: Orientações básicas do Ministério de Turismo.O que é preocupante, já que cada vez mais os turistas estão demonstrando interesse com as questões socioambientais.

Falta muito a ser feito por parte dos governantes e dos proprietários, para que o balneário se transforme em um local que seja trabalhado de forma correta o ecoturismo utilizando como ferramenta a conscientização e a educação ambiental para o local.

Numa tentativa de sensibilizar os proprietários do balneário a fim de conscientizá-los para os problemas que o estabelecimento apresenta, esta pesquisa será disponibilizada para os mesmos. A partir disso, espera-se que o ecoturismo e a educação ambiental sejam trabalhados corretamente, com o intuito de repassar o conhecimento adquirido aos turistas para que estes também se tornem cada vez mais responsáveis por suas atitudes com o meio ambiente.

\section{Referências Bibliográficas}

ALMEIDA, E.F.; NUNES, J.R.S. Educação ambiental e ecoturismo em área natural: Um estudo de caso no mirante camping e lazer no município de Tangará da Serra - MT. Uniciências (UNIC), v. 14, p. 359-383, 2010.

BRASIL. Ministério do Turismo. Ecoturismo: Orientações básicas/ Ministério do Turismo, Secretária Nacional de Políticas de Turismo, Departamento de Estruturação, Articulação Ordenamento Turístico, Coordenação Geral de Segmentação. - Brasília: Ministério de Turismo, p. 60, 2008.

COSTA, P.C. Ecoturismo. São Paulo: Aleph: 2002. - (Coleção ABC do turismo).

COSTA, N.M.C.; COSTA, V.C. da. Educação Ambiental pelo Ecoturismo, em Unidades de Conservação: uma proposta efetiva para o Parque Estadual da Pedra Branca ( PEPB) - RJ. In: PEDRINI, A.G. (org). Ecoturismo e a Educação Ambiental, 2005. Disponível em: $<$ http://reari.com/wpcontent/uploads/2008/09/arquivocoletaneaeaecoturismo300804.pdf> Acessado em: 17 de Fevereiro de 2012.

DIAS, G F. Educação ambiental: princípios e praticas $-6^{\circ} \mathrm{ed}$. rev. e ampl. pelo autor - São Pulo: Gaia; 2000.

FARIA M.O. O mundo globalizado e a questão ambiental. In: NEIMAN, Z. (org). Meio Ambiente, Educação e Ecoturismo. São Paulo: Manole, p. 415, 2002.

FENNELL, D.A. Ecoturismo: uma introdução. São Paulo: Contexto, 2002.

GUIMARÃES, R.G. ;ZAVALA, A.A.Z. A atividade Turística da Região de Nobres/MT como instrumento de Desenvolvimento Econômico Sustentável. Revista de Estudos Sociais- ano 2011, n.22, v.2, 2009.

LADEIRA, A.S. et al. O perfil dos visitantes do parque estadual do Ibitipoca (PElb), Lima Duarte, MG. Rev. Árvore [online]. 2007, vol.31, n.6, pp. 10911098. ISSN 0100-6762. 
MARTINS JÚNIOR, O.S. Turismo e lazer para a terceira idade. 2005. $145 \mathrm{f}$. Monografia (Especialização em Turismo, Cultura e Lazer)-Universidade de Brasília, Brasília, 2005.

MENDONÇA, R.; NEIMAN, Z. Discurso, Desejo e Realidade. In: NEIMAN, Z. (org). Meio Ambiente, Educação e Ecoturismo. São Paulo: Manole, p. 159-175, 2002.

MINAYO, M.C.S. (Org.). Pesquisa social: teoria, método e criatividade. $20^{\underline{a}}$ edição. Rio de Janeiro: Vozes. p.108.1994.

NEIMAN, Z.; RABINOVICI, A. O cerrado como instrumento para a educação ambiental em atividades de ecoturismo. In: NEIMAN, Z. (org). Meio Ambiente, Educação e Ecoturismo. São Paulo: Manole, p. 135-158, 2002.

PEDRINI, A.G; MESSAS, T.P; PEREIRA, E.S; GHILARD-LOPES, N.P; BERCHEZ, F.A. Educação ambiental pelo ecoturismo numa trilha marinha no parque estadual da ilha Anchieta, Ubatuba (SP). Revista Brasileira de Ecoturismo, São Paulo, v.3, n.3, 2010, pp.428-459.

PEDRINI, A.G. Ecoturismo, Interpretação e Educação Ambientais: consensuando conceitos. In: Congresso Nacional de Ecoturismo, 2007, Itatiaia. Anais do Congresso Nacional de Ecoturismo, 2007. v. 1.

PEDRINI, A.G. Em busca da Educação Ambiental no (eco) turismo brasileiro: Um ensaio. Anais do I Encontro interdisciplinar de ecoturismo em unidades de conservação. Estado do Rio de Janeiro, 2005. Disponível em: < http://reari.com/wpcontent/uploads/2008/09/artigoembuscaeaecoturismoieco uc20051.pdf. Acessado em: > 17 de Fevereiro de 2012.

PIRES, P.S. Dimensões do ecoturismo. São Paulo:SENAC, 2002.

PRONEA/ Programa Nacional de educação ambiental. Ministério do Meio Ambiente, Diretoria de Educação Ambiental; Ministério da Educação. Coordenadoria Geral de Educação Ambiental. - 3. ed - Brasília: Ministério do Meio Ambiente, p. 102, 2005.

SATO, M. Educação para o Ambiente Amazônico. Tese de Doutorado apresentada ao Programa de Pós-Graduação em Ecologia e Recursos Naturais, do Centro de Ciências Biológicas e da Saúde da Universidade Federal de São Carlos, 1997.

SAUVÉ. L. Educação Ambiental: Possibilidades e limitações. Educação e Pesquisa. São Paulo, v.31, n.2, p. 317-322, maio/ago. 2005.

TOLEDO, F.R.; PELICIONI, F.C.M. Educação Ambiental nos parques estaduais Paulistas. Revista Brasileira de Ciências Ambientais, n.3, 2006.

VAZ. D.M.S. Perfil dos visitantes do Parque Municipal do Açude da Concórdia - Valença (RJ). Revista Brasileira de Ecoturismo, São Paulo, v.3, n. 1, 2010. pp. 109-120.

XAVIER, C. V. Educação Ambiental: uma alternativa para amenizar os impactos ambientais do Ecoturismo. Revista Global Tourism, v. 2, Nov. $2005 . \quad$ (online) Disponível em $<$ http://www.periodicodeturismo.com.br/site/artigo/pdf/Educação\%20Ambient al\%20uma\%20alternativa\%20para\%20amenizar\%20os\%20impactos\%20am bientais\%20do\%20Ecoturismo.pdf>Acessado em: 17 de Fevereiro de 2012. 


\section{Notas:}

${ }^{1}$ Colocou-se apenas balneário, pois o mesmo é uma propriedade privada e optou-se por não divulgar o nome do estabelecimento.

${ }^{2} \mathrm{O}$ termo funcionário encontra-se no singular, pois somente uma pessoa respondeu o questionário, já que no estabelecimento mora apenas um casal de caseiros.

Maysa Teodoro Lemes: Universidade Estadual do Estado de Mato Grosso, Tangara da Serra, MT, Brasil.

E-mail:maysa_lemes@hotmail.com

Link para o currículo Lattes: http://lattes.cnpq.br/3677736948556671

Josué Ribeiro da Silva Nunes: Universidade Estadual do Estado de Mato Grosso, Tangara da Serra, MT, Brasil.

E-mail: josue@unemat.br

Link para currículo Lattes: http://lattes.cnpq.br/3292016056510295

Paula Alexandra Soares da Silva Nunes: Centro de Ensino de Jovens e Adultos Antonio Casagrande, Tangará da Serra, MT, Brasil.

E-mail: paulajoso@gmail.com

Link para currículo Lattes: http://lattes.cnpq.br/7036746219887400

Simone Santos de Oliveira: Universidade Estadual do Estado de Mato Grosso, Tangara da Serra, MT, Brasil.

E-mail: siimone_@msn.com

Link para currículo Lattes: http://lattes.cnpq.br/5663105418538638

Data de submissão: 13 de março de 2013

Data de recebimento de correções: 27 de setembro de 2013

Data do aceite: 25 de janeiro de 2014

Avaliado anonimamente 